\title{
A Comparative Study of Novel Translation from the Perspective of Feminist Translation Theory: A Case Study of the Two Chinese Versions of Persuasion* $^{*}$
}

\author{
Yuying Li \\ Foreign Languages College, Jiangxi Normal University, Nanchang, China \\ Yuming Zhang \\ Foreign Languages College, Jiangxi Normal University, Nanchang, China
}

\begin{abstract}
Female translators differ from male translators in the choice of the original texts, the adoption of translating strategies and the diction features of the translation, etc. From the perspective of Feminist Translation Theory, the paper made a comparative study of the two translated versions of Persuasion by Qiu Yin, a woman translator and Sun Zhili, a man translator, in the aspects of female preferences of exclamatory sentences and rhetorical questions, sentence final particles, reduplicated words as well as prefaces and footnotes. The identity of the female translator is reflected in Qiu's version in comparison of Sun Zhili's.
\end{abstract}

Index Terms-Persuasion, feminist translation theory, female translators

\section{INTRODUCTION}

Persuasion is a literary work that has withstood the test of time. Written by Jane Austen, the nineteenth-century English novelist, the novel has sparked constant interest and academic concern of numerous scholars, most of whom studied the classic from the literature, social or linguistic perspectives. The translations of the novel promote the spread of the novel throughout the world. Among the various translated versions in different languages there are also several Chinese translations of the classic and this study selects two versions, one by Qiu Yin, a female translator and the other by Sun Zhili, a male translator, as the corpus to conduct a comparative study from the perspective of Feminist Translation Theory, to explore and reveal the gender consciousness of female translators in contrast with male translators.

\section{LITERATURE REVIEW}

Feminist literary criticism was born in the Second European and American Women's Liberation Movements in the 1960s, and wherein Feminist Translation Theory derived in the 1980s. The pioneers of the theory include Sherry Simon, Louise von Flotow and Spivak, Gayatri Chakravorty. Simon's (1996) Gender in Translation is the first comprehensive study of feminist issues in translation theory and practice. She was concerned with the existence of female translators and criticized the tendency in the translation study field to belittle female translators and their translations, in the hope to alert translation theorists to the range of issues suggested by gender. Flotow (1997) concluded three major translation strategies of feminist translation theory, which are complement, notes and preface, as well as hijacking. Spivak (1992) held that the task of the feminist translator is to consider language as a clue to the workings of gendered agency and he attached great importance to the voices of the females in the Third World.

Feminist translation theory was first introduced into China by Zhu Hong in the 1980s, but it was not until 2000 that the theory has been concerned by the academic circles. The first scholars were dedicated to the introduction of the theory and some tentative studies. Liao Qiyi (2002) holds the opinion that imperfect as feminist translation theory is, it acknowledges the influences of specific cultural and political factors have on people's notions and translation process. Ge Xiaoqin(2003) points out that translation is a complicated process involving collision and fusion between diverse cultures while feminist translation theory means to intervene in the cultures involved in the translating and to rewrite the discourse. Liu Junping (2004) delves into the interrelations among translation, the female, the author, the text, the translator and the readers. Based on Simon's and Flotow's researches, Xu Lai (2004) reprimands the discrimination against feminist translation and female translator, playing a major role in the fight for feminist dignity and equality. In summary, feminist translation theory proposes that translation is a recreation on the basis of the original on the one hand,

\footnotetext{
${ }^{*}$ Sponsored by Multimodal Interaction Research in Foreign Language Teaching, a Social Science Project of Jiangxi (17YY04).
} 
and on the other hand puts emphasis on the influence of gender difference on translation.

The years from 2005 to 2007 witnessed Chinese scholars' researches on feminist translation theory combined with translation texts by female translators. The representatives include Chen Yu and Chen Lin (2005) who explore the translation strategies and methods of protruding the female discourses in their Feminist Rewriting of the Discourses - With a Comparative Study on the Two Translation Versions of Jane Eyre and Yang Xue (2007) who, in her Translators' Feminist Consciousness and the English Translating of Zang Hua Ci, analyses the three translations of Zang Hua Ci in light of the sound, word, sentence and text levels and concludes that not only female translators but also male translators contain feminist consciousness.

Since 2008, there also have been some skeptical voices. There might be deficiencies of the theory itself that call for improvement and need perfecting. Modern translators and translation researchers should treat the theory by a developmental view and dialectical attitude. Only in this way can feminist translation theory be employed as a boon in translation practice and more and greater achievements made in the study on the theory.

\section{A Comparative Study of the Two Translated Versions of Persuasion}

The following section entails the main body of the study. The research will be performed in some typical dimensions that could adequately demonstrate the gender difference between male and female translators in the respects of female preference for exclamatory sentences and rhetorical questions, for sentence final particles and for reduplicated words. This section will take a focalization analysis of the samples from Qiu's and Sun's translated versions from Persuasion.

\section{A. Female Preference for Exclamatory Sentences and Rhetorical Questions}

In his Language and Women's Place Robin Lakoff (1975) proposes some linguistic features of female discourses, including female tendency to use exclamatory sentences and questions in making statements, to seek for the approval from the addressees and female preference for rhetorical questions when asking questions. Based on the related experimental analysis, Holmes puts forth that, compared with men, women tend to utilize disjunctive questions in order to ensure a smooth exchange and interaction. Chinese women also reveal a propensity to use disjunctive questions to express an affirmation.

\section{Example 1:}

The Original: Captain Harville has no thought but of going.

Qiu's Vesion: 哈维尔上校真想去呢!

Sun's Version: 哈维尔舰长是一心一意要去的。

Analysis: Anne, the heroine, held a party for which she enjoined Mrs. Musgrove to pass on the word to Captain Harville and Captain Wentworth, inviting them to the party. The above example is Mrs. Musgrove's reply to the request. The original is a statement, and Sun Zhili's translation follows the source language in the sentence pattern as a statement, stating the inornate fact the Captain Harville would love to attend the party while Qiu Yin's translation, by changing the statement into an exclamation, representing female linguistic preference. As the employment of exaggerations and modifiers and the modulations of tones unveil more affective variables in female language (Qian Jin, 2004), the exclamation contains stronger emotional coloring, leaving the readers a distinct impression that Captain Harville was keen on the oncoming party.

\section{Example 2:}

The Original: Could she believe it a week ago- three hours ago!

Qiu's Vesion: 一个星期之前, 甚至在三小时之前, 她能相信这一点吗?

Sun's Version: 这在一周之前, 甚至在三个钟头以前, 简直叫她无法相信！

Analysis: On seeing Anne explaining an Italian song to Elliot, Captain Wentworth mistook it as Anne's affection for the latter and quitted the concert out of jealousy and outrage. When Anne saw the reason why Captain Wentworth left the concert, she was astonished and at the same time complacent as well. The sentence is a description of Anne's surprise. The original is an exclamatory sentence, and Sun Zhili, the male translator, simply reproduces the sentence pattern to reveal Anne's astonishment. In a conversation with the opposite sex, women are usually passive and humble. They often use questions, disjunctive questions or modal verbs, taking them as a means to proceed with the conversation or to attract attention from the opposite sex (Su Wenjin, 2000). The point is illustrated by the situation in which Qiu Yin, the female translator, converted the original exclamation into a rhetorical question, succeeding in capturing the readers' attention as well as displaying Anne's astonishment.

\section{B. Female Preference for Sentence Final Particles}

In the 1920s, Lakoff studied female linguistic features and pointed out the female preference for sentence final particles such as “吧”, “啊”, “吗”, “呢”, etc. The use of sentence final particles makes the request, question or statement less rigid and more courteous. In China, women utilize sentence final particles more frequently than men do, which coincides with the norms for females in the traditional Chinese culture. The use of sentence final particles in translation demonstrates a distinguishing feature in the female utterance, revealing to the readers the identification and an evident image of a female translator. 


\section{Example 3:}

The Original: Do promise me.

Qiu's Vesion: 请答应我吧

Sun's Version: 请答应我。

Analysis: This is what Anne said to Mrs. Musgrove when she pleaded the latter to pass on her invitation to Captain Harville and Captain Wentworth to the party. It's obviously a request, so Mr. Sun Zhili bluntly translated it into “请答应 我". Males are deemed as of higher status in the society, and therefore they assume a dominant style in social discourse (Su Wenjin, 2000). As is illustrated in Sun's translation of the sentence, “请答应我” carries an imperative tone, liable to invoke a resentment from the readers by its stiffness and might, which does not conform with the gentle nature of the speaker. On the contrary, Qiu's addition of a sentence final particle "ba" softens the plea, corresponding to the mild and courteous personality of Anne, the speaker.

\section{Example 4:}

The Original: Even, if your own feelings were reluctant or indifferent, to consider what powerful supports would be his! Was it not enough to make the fool of me which I appeared? How could I look on without agony?

Qiu's Vesion: 即使你本人的感情比较勉强或冷漠, 可是支持他的力量是多么强大啊! 这难道不足以把我变成 当时那个俊样子吗? 我怎能眼看着这一切而不感到难过呢?

Sun's Version: 即使你自己心里不愿意, 或是不感兴趣, 想想看他有多么强大的后盾! 我看上去俊乎乎的, 难道这还不足以愚弄我? 我在一旁看了怎能不痛苦?

Analysis: The above discourse occurred in an enthusiastic conversation between Anne and Captain Wentworth when the latter became aware of the fact that he himself had been in love with the former and felt furious at the intimacy Anne showed towards her cousin and finally couldn't help saying out loud his affection. The addressee is a women the speaker profoundly loved and therefore, although he was to unleash his outrage and indignation, he could not did it wantonly or reprimand Anne but with some gingerliness, his mood at the moment being actually a contradictory one. The meaning of language is determined by the specific context of the utterance. To achieve an accurate comprehension of the original, the translator is obliged to infer the genuine intention of the original author. He should combine the semantics with the specific context before representing to the readers of the translation the information encoded in the original. In translation, what should be taken into account is not only the language context, but also the restrictive function of the communicative context (Yang Junfeng, 2005). In the above example, the female translator complemented three sentence final particles “啊”, “吗”, “呢”, mitigating the tone of the reproach and embodying Captain Wentworth's tender care for Anne. Conversely, the lack of the sentence final particles in the male translator unfolded a distorted image of Captain Wentworth, which appeared to be more commanding than he really was.

\section{Female Preference for Reduplicated Words}

As an enhancement expression model of the adjective or the adverb related, reduplicated words are commonplace in everyday Chinese and are especially to the liking of females when they attempt to describe an issue or narrate an event to impress the audience. The present study contributes to the conclusion that female preference for reduplicated words is a distinguishable mark which female language bears in contrast to male language.

\section{Example 5:}

The Original: There could not be an objection. There could be only a most proper alacrity, a most obliging compliance for public view; and smiles reined in and spirits dancing in private rapture.

Qiu's Vesion: 不可能有反对意见, 有的只是恰如其分的欣然同意, 是做给旁人看的乐于助人的顺从, 他们心 中却是乐滋滋的,高兴得发狂。

Sun's Version: 这不可能遭到反对。在公众看来, 只能见到温特沃斯舰长极有分寸、极有礼貌地欣然接受了。 他收玫起笑容, 心里暗中却欣喜若狂。

Analysis: Charles had intended to escort Anne home, but when he saw Captain Wentworth in the company of the latter, he meant to transfer the task to the captain, so that he himself was free to go to the gunsmith's. Though apparently composed, Captain Wentworth was on top of the world to accept the request in that he was craving to have an opportunity to be alone with Anne. The original text is a description of Captain Wentworth's response to Charles' plea. Both Qiu's and Sun's versions are adequate at conveying the exhilaration from the inner heart of Captain Wentworth but utter equivalence between the target language and the source language is virtually unattainable due to the affecting factors of historical background, communicative environment, and such factors as the ideology, aesthetic taste and the translation purpose of the translator (Zhong Wen, 2011). The Chinese female preference of the reduplicated words invalids “乐滋滋” in Qiu's version which vividly pictures Captain Wentworth's heartfelt delight in spite of the omission of "smiles" in the translation, exhibiting the character depicted on cloud nine.

\section{Example 6:}

The Original: And she answered the question, smiling also.

Qiu's Vesion: 安妮也笑盈盈地回答了这个问题。

Sun's Version: 安妮同样嫣然一笑, 答道。 
Analysis: In a talk with Captain Harville, Anne remarked that women would not forget the man they loved once they have given their heart. At Captain Harville's disputation on the opinion, Anne explained to him the reasons supporting her viewpoint and the discourse is a depiction of Anne's appearance and expression when she was expounding her view. There is a consensus between the two renderings in the presentation of Anne's smiling expression when she was replying Captain Harville. However, in the choice of the topic, as well as in the volume, the manners and the strategy of the discourse, there are gender differences to the diversified degrees (Lv Jing, Hu Zhiqing, 2001; Xu Lisheng, 1997). As is illustrated in the translations of the word "smiling", Sun Zhili transformed the single word into a Chinese four-character structure “嫣然一笑”, while Qiu’s translation employs “笑盈盈”, a "verb plus reduplicated phrase” pattern to depict a lifelike smiling Anne, vividly portraying the character as a confident and composed girl, leaving a deeper and more favorable impression on the readers.

\section{Female Preference of Making a Point by Prefaces and Footnotes}

Feminist influence on translation and translation studies is most readily visible in the metatexts - the prefaces and footnotes that have been added to the works published since the late 1970s. In these texts a noticeable trend is the developing sense of self exhibited by translators, increasingly aware that their identities as gendered rewriters enter into their work. Translators are introducing and commenting on their work, and offering explanations for it (Flotow, 1997).

Example 7:

Qiu's Preface: ......在书中, 奥斯丁还通过她塑造的新型妇女形象——克罗夫特太太, 说明了妇女在婚姻和家 庭中应有的地位, 歌颂了妇女的社会作用.....事实上, 安妮确实是一位正直、无私、乐于助人、对爱情坚贞不 渝的女性......安妮同情弱者, 助人为乐.....安妮还是一个临危不乱、善于决断的女性。她的智慧和处理事务的 能力大大超过男子汉......

Analysis: Prefacing is a common means of translation, but female translators regard it as a kind of translation convention. They apply "Preface" to intervene in the text. In the preface, female translators often explain the main idea of the original work, introduce the purpose of their translation, summarize their translation strategies, and state their own views. There is no preface in Sun Zhili's Persuasion. However, in Qiu's Persuasion, she has exerted further influence by writing the preface that draw readers' attention to the work of herself as a translator and the historical, literary as well as biographical research that accompanies the translated text. In her preface, she strongly expresses her praise to the heroin Anne and Mrs. Croft, explains women's proper position in marriage and family, and describes women's important social role. Finally, Qiu Yin writes her name at the end of the preface, which makes the identity of the female translator visible to the readers. This is all part of a concerted move away from the classical 'invisible' translator (Flotow, 1997).

Example 8:

The Original: IR Walter Elliot, of Kellynch Hall, in Somersetshire, was a man who, for his own amusement, never took up any book but the Baronetage.

Qiu's Vesion: 萨默赛特群凯林奇府的沃尔特. 艾略特爵士, 每当自己消遣时, 总是捧着一本《从男爵录》『 从不阅读其他任何书籍。

（1)《从男爵录》中收集了英国历代从男爵的资料。从男爵可以称为爵士，但并不属于贵族。可是沃尔特. 艾略 特爵士总是洋洋得意地翻阅着这本《从男爵录》, 充分反映出他的浅薄。

Sun's Version: 萨默赛特郡凯林奇大厦的沃尔特.埃利奥特爵士为了自得其乐，一向什么书都不沾手，单单爱 看那《准爵录》。

(2)系指 1808 年初次出版的 J.德布雷特编纂的《英国准爵录》, 分上、下两卷。

Analysis: In this example, both Qiu Yin and Sun Zhili have made a footnote but for different purposes. Sun Zhili just objectively introduces the book Baronetage to the readers while Qiu Yin, in addition to making an objective introduction, also takes the opportunity to express some of her own views and satirizes IR Walter Elliot, who is a crucial male figure in the novel. In Qiu's opinion, IR Walter Elliot is a vain and self-righteous man. It is often considerably easier for a translator to proclaim his or her own opinions in footnotes than to actually take action in the process of translation (Flotow, 1997). Obviously, Qiu's footnote marks and explains her motivations and interventions skillfully.

Example 9:

The Original: And, if I dared, I would breathe my wishes that the name might never change.

Qiu's Vesion: 如果我有胆量, 我愿倾吐我的心愿: 希望这姓名永远不要变 (1)。(1)在英国, 姑娘结婚后要改用夫 家姓氏。这里是婉转的求婚, 因为艾略特先生与安妮同姓。

Sun's Version: 假如我不揣冒昧的话, 我倒要希望这个名字永不改变。

Analysis: This is what Mr. Eliot said to Anne. If this sentence is translated directly into Chinese, readers can understand the superficial meaning of this sentence easily. But some readers may not see the information hidden behind this sentence because of cultural differences-Mr. Eliot is proposing to Anne euphemistically when he is saying this sentence. Sun Zhili has neglected this point when he translates this sentence. He just translates it literally without any additional explanation. As a woman, Qiu Yin's mind is more delicate and sensitive than men's, so when she translates 
this sentence, she adds a footnote, introducing the cultural background behind this sentence and the important information hidden behind it, expressing her inner thoughts, thus enabling the readers to understand the content of this part more thoroughly.

\section{CONCLUSION}

The above in-depth comparison of Qiu Yin's and Sun Zhili's translated versions of Persuasion evidently illustrates the gender differences of the linguistic features in translation. Female translators usually have a more nuanced mind that enables them to perceive the various actions and states of mind of the characters in the novels and so there is a propensity in their translation to employ exclamatory sentences, rhetorical questions, reduplicated words and sentence final particles to present the personalities of the characters to the target readers of the translated version, accurately conveying the context of the original. In doing so, they reflect their female image in their translation. In addition, with gender viewed as an integral factor in textual production, attention has increasingly focused on politically engaged translators, who are conscious of their influence on the text and may seek to impose it overtly. Therefore, female translators have a preference for prefaces and footnotes in order to state their opinions more easily and make themselves visible to the readers.

\section{REFERENCES}

[1] Barbara Godard. (1990). Theorizing Feminist Discourse/Translation. In Susan Bassnett and Andre Lefevere(Ed.), Translation and Culture. London: Frances Printer, 87-96.

[2] Chen Yu \& Chen Lin. (2005). Feminist Rewriting of the Discourses-With a Comparative Study on the Two Translation Versions of Jane Eyre. Journal of Shanxi Teachers University, 6, 120-123.

[3] Ge Xiaoqin. (2003). The Essence of Feminist Translation. Foreign Languages Research, 6, 35-38.

[4] Hu Zuoyou, Hu Xiaojuan \& Li Erwen. (2013). Reception of Feminist Translation Theory in China. Academics, 3, 152-160.

[5] Jane, Austen. (2009). Persuasion. Beijing: Foreign Language Teaching and Research Press.

[6] Lori Chamberlain. (1988). Gender and the Metaphorics of Translation. The University of Chicago Press Journals, 13, 454-472.

[7] Liu Jianda. (1998). Sex Discrimination and Liberation in Language. Journal of Shandong Foreign Language Teaching, 1, 8-25.

[8] Liu Junping. (2004). Towards An East-West Discourse on Feminist Translation Studies. Chinese Translators Journal, 4, 3-6.

[9] Lv Jing \& Hu Zhiqing. (2001). A Study on Gender Differences in Language. Journal of HUST Social Science Edition, 15, 117-120.

[10] Liao Qiyi. (2002). Re-write the Myths: Feminism and Translation Studies. Journal of Sichuan International Studies University, $18,106-109$.

[11] Louise von Flotow. (1997). Translation and Gender: Translating in the Era of Feminism. Manchester: St. Jerome Publishing.

[12] Qiu Yin. (2015). Persuasion. Shanghai: Shanghai Translation Publishing House.

[13] Qian Jin. (2004). A Survey of Gender Differences in Language. Literature Studies, 6, 47-50.

[14] Robin Tolmach Lakoff. (1975). Language and Women's Place. New York: Harper \& Row.

[15] Spivak, Gayatri Chakravorty. (1993). The Politics of Translation. Spivak, Gayatri Chakravorty(Ed.), Outside in the Teaching Machine. New York: Routledge, 179-200.

[16] Sherry Simon. (1996). Gender in Translation: Cultural Identity and the Politics of Translation. New York: Routledge.

[17] Su Wenjin. (2000). Overview of Study on the Causes of Gender Differences in Language. Journal of Longyan Normal College, $1,89-92$.

[18] Sun Zhili. (2016). Northanger Abbey \& Persuasion. Nanjing: Yilin Press.

[19] Xu Lai. (2004). "Rewriting" in the Name of Feminine-The Significance of the Feminism Translation Theory in the Study of the Translator's Subjectivity. Chinese Translators Journal, 4, 16-19.

[20] Xu Lisheng. (1997). Study on Gender Differences in Discourse Style. Foreign Languages, 1, 42-47.

[21] Yang Junfeng. (2005). Textual Adaptation and Pragmatic Translation. Foreign Languages and Their Teaching, 11, 47-50.

[22] Yang Xue. (2007). Translators' Feminist Consciousness and the English Translating of Zang Hua Ci. Journal of Shanghai University, 1, 125-130.

[23] Zhong Wen. (2011). Contextual Adaptability and Pragmatic Translation. Academics, 11, 163-173.

Yuying Li was born in Jiangxi Province, China in 1964. She is currently a professor in Translation Theory and Practice, Jiangxi Normal University, Nanchang, China. She has published dozens of papers in both Chinese and international academic journals.

Yuming Zhang was born in Anhui Province, China in 1994. She is currently a postgraduate in Translation Theory and Practice, Jiangxi Normal University, Nanchang, China. 